PDFlib PLOP: PDF Linearization, Optimization, Protection

Page inserted by evaluation version www.pdflib.com - sales@pdflib.com 


\title{
Reversibility of Serum Removal Effects on IGF-II mRNA in Human Neuroblastoma Cells
}

\author{
DONNA M. MARTIN AND EVA L. FELDMAN \\ Department of Neurology \\ The University of Michigan \\ Ann Arbor, Michigan 48104
}

Insulin-like growth factor II (IGF-II) is highly expressed at the mRNA and protein levels in SH-SY5Y human neuroblastoma cells. ${ }^{1,2}$ SH-SY5Y cells also express type I and type II IGF receptors, ${ }^{2,4}$ and respond to IGF-II with increased DNA synthesis and neurite outgrowth, ${ }^{4}$ suggesting the presence of an IGF-II-mediated autocrine growth mechanism. Based on these results, we hypothesized that the rate of SH-SY5Y cell proliferation is partly determined by the level of IGF-II gene expression, and that IGF-II expression may be serum dependent. We tested this hypothesis using northern analysis to determine the effects of removal and subse-

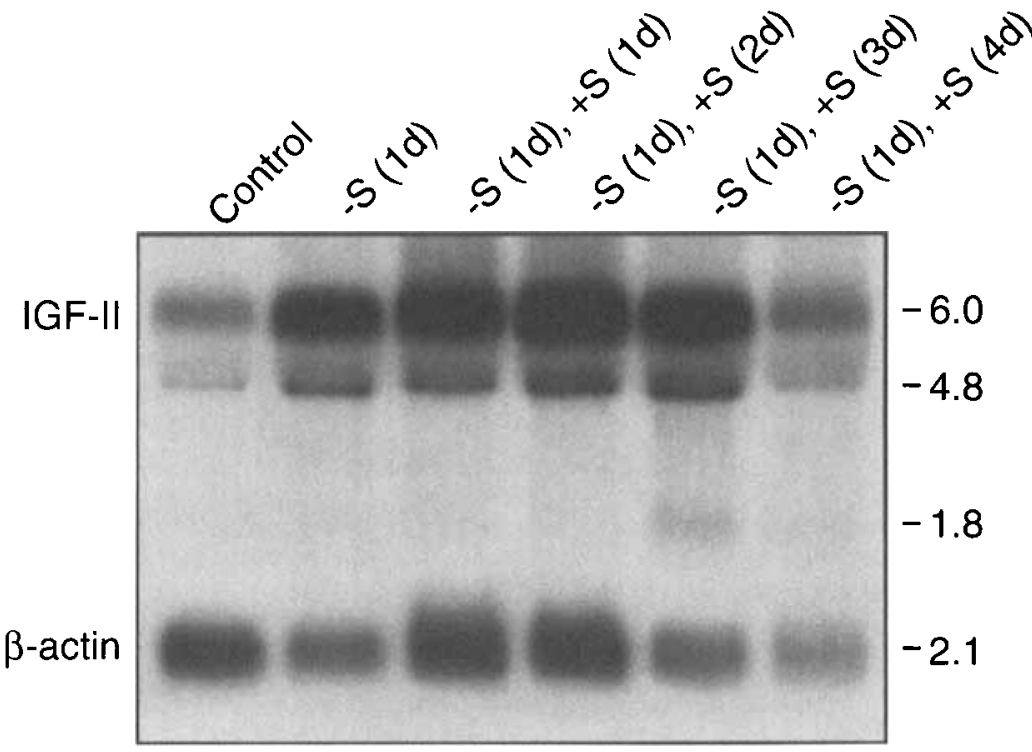

FIGURE 1. Northern analysis of IGF-II mRNA. SH-SY5Y cells were plated $\left(3.7 \times 10^{6}\right.$ cells $/ \mathrm{cm}^{2}$ in T150 flasks) and cultured for 2 days in $10 \%$ calf serum and DMEM. Cells were rinsed with DMEM, and DMEM added. After 1 day, the medium was removed and DMEM + $10 \%$ calf serum added. RNA was isolated either before serum removal (no rinse), 1 day after serum (S) deprivation, or 1,2,3, or 4 days after transfer back to serum, as indicated in the legend. Total RNA was electrophoresed and northern analysis performed as described, ${ }^{2}$ with ${ }^{32}$ P-cDNA labeled probes for human IGF-II and $\beta$-actin. 
quent addition of serum on cultured SH-SY5Y cell IGF-II mRNA levels. RNA was analyzed from cells that were serum deprived for one day or cells that were serum deprived and subsequently transferred to serum-containing media for one to four days.

SH-SY5Y cells expressed three IGF-II mRNA transcripts $(1.8,4.8$, and $6.0 \mathrm{~kb})$, of which the $6.0-\mathrm{kb}$ transcript was the most abundant, as previously described. ${ }^{2} \mathrm{~A}$ $2.1-\mathrm{kb} \beta$-actin mRNA was also detected, and served as a control for the amount of

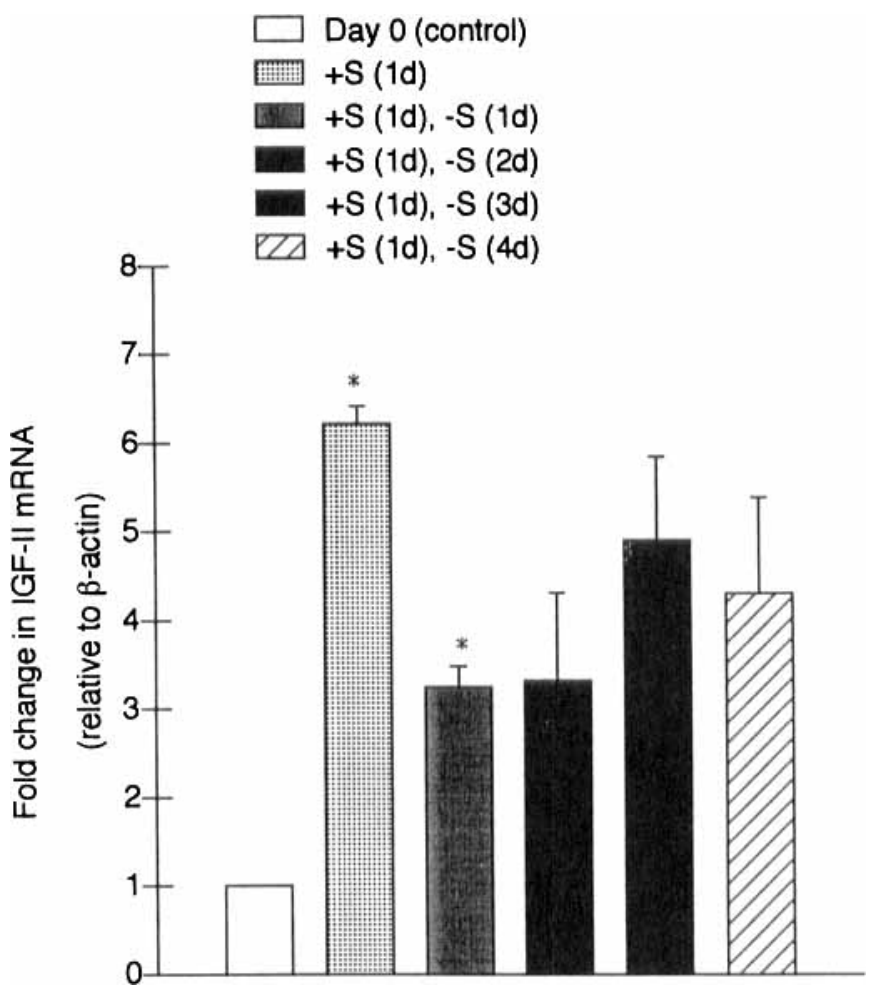

FIGURE 2. Densitometric analysis of IGF-II mRNA. Optical densities of the 6.0-kb IGF-II and $2.1 \mathrm{~kb} \beta$-actin bands for each lane of several autoradiographs like that shown in FiguRE 1 were densitometrically quantitated, and IGF-II mRNA expressed as a percentage of the untreated control relative to $\beta$-actin. ${ }^{*} p<0.05$ relative to untreated, day 0 control levels by unpaired, two-tailed $t$-test.

RNA loaded onto the gel. Levels of the 6.0-kb IGF-II mRNA increased by 6-fold after a one-day serum deprivation (FIGURES 1 and 2, lanes 1 and 2). One day following the subsequent addition of serum to SH-SY5Y cells, IGF-II mRNA was reduced to 3-fold above untreated control levels (FIGURES 1 and 2, lanes 1 and 3). Two, three, or four days after subsequent serum addition, SH-SY5Y cell IGF-II mRNA levels were not significantly different from untreated control levels (FIGURES 1 and 2 , compare lane 1 with lanes $3,4,5$, and 6). 
These observations indicate that steady-state IGF-II mRNA levels increase with serum removal and are partially reversed by the addition of serum. IGF-II mRNA transcripts in stably transfected mouse cells are differentially expressed in a serumdependent fashion. ${ }^{3}$ We observed no changes in the relative abundance of the three IGF-II mRNA transcripts in human SH-SY5Y cells, suggesting that species-specific (mouse vs. human) factors may be important in the regulation of IGF-II gene expression.

In summary, we found that IGF-II mRNA levels in SH-SY5Y cells are increased with serum deprivation, and partially reversed to untreated control levels by subsequent addition of serum-containing media. Regulation of IGF-II gene expression by serum may be associated with changes in SH-SY5Y cell growth. Indeed, we have shown elsewhere that IGF-II gene expression is decreased with growth inhibition by the cytokine interferon- $\gamma{ }^{1}$

\section{REFERENCES}

1. Martin, D. M., R. O. Carlson \& E. L. Feldman. 1993. Interferon- $\gamma$ inhibits DNA synthesis and IGF-II gene expression in human neuroblastoma cells. J. Neurosci. Res. 34: 489-501.

2. Martin, D. M., D. Yee, R. O. Carlson \& E. L. Feldman. 1992. Gene expression of the insulin-like growth factors and their receptors in human neuroblastoma cells. Mol. Brain Res. 15: 241-246.

3. Meirsman, D., P. E. Holthuizen, J. L. Van den Brande \& J. S. Sussenbach. 1991. Specific endonucleolytic cleavage of IGF-II mRNAs. Biochem. Biophys. Res. Commun. 179: $1509-1516$.

4. Recio-Pinto, E. \& D. N. Ishil. 1988. Insulin and insulinlike growth factor receptors regulating neurite formation in cultured human neuroblastoma cells. J. Neurosci. Res. 19: $312-320$. 